\title{
LNDO/S PERTCI Electronic Spectra of Some Radical Cations*
}

\author{
Andreas Heidenreich, Norbert Münzel, and Armin Schweig \\ Fachbereich Physikalische Chemie, Universität Marburg, Marburg, FRG
}

Z. Naturforsch. 41 a, 1415-1424 (1986); received August 20, 1986

\begin{abstract}
A theoretical approach to the interpretation of UV/VIS spectra of radical cations is made LNDO/S PERTCI calculations including all singles and doubles with respect to the ion ground and excited state main configurations are made. Evaluations of the oscillator strengths are carried out using the full ground and ion states CI vectors. The method is applied to [trans-butadiene] ${ }^{+}$, $[\text { all-tans-hexatriene }]^{+}, \quad$ [all-trans-octatetraene $]^{+}, \quad[\text { cis-butadiene }]^{+}$, [all-cis-hexatriene $]^{+}, \quad[$ transstilbene $^{+}$, [biphenyl] $]^{+}$, [diphenylacetylene $]^{+}$, [benzocyclobutene $]^{+}$, and [o-xylylene $]^{+}$. Calculated electronic excitation spectra for these systems are presented. They are compared with the UV/VIS spectra in low temperature matrices. It is shown, that LNDO/S PERTCI results can be of help in the interpetation of UV/VIS spectra of cations and thus in the difficult task of identifying such systems or cationic reaction products of cations.
\end{abstract}

The LNDO/S [2, 3] PERTCI method [4] was developed for the prediction of Koopmans valence electron vertical ionization energies (IPs) and electronic transition energies $(\Delta E \mathrm{~s})$ as well as oscillator strengths ( $f$ values) of organic molecules. Following the main interest in the authors' group the method was predominantly used over the years for the calculation of Koopmans ${ }^{1}$ and - since some time for non-Koopmans [5-8] ionization energies (leading to satellites or shake-up bands in photoelectron (PE) spectra). Due to the close connection between the ionization spectrum (or its experimental counterpart, the PE spectrum) of a molecule ${ }^{2}$ and the electronic spectrum (or the UV/VIS absorption spectrum) of its radical cation ${ }^{2}$ we decided to apply the LNDO/S PERTCI approach to the calculation of the electronic spectra of some radical cations of recent interest, namely [trans-butadiene $]^{+}$, [all-transhexatriene $]^{+}, \quad[\text { all-trans-octatetraene }]^{+}, \quad[$ cis-butadiene $]^{+}, \quad[\text { all-cis-hexatriene }]^{+}, \quad[\text { trans-stilbene }]^{+}, \quad[\mathrm{bi}-$

* Part 109 of Theory and Application of Photoelectron Spectroscopy; for part 108 see [1].

${ }^{1}$ See [1] and numerous foregoing papers in the series of papers Theory and Application of Photoelectron Spectroscopy; see in particular [3], where a statistical analysis of the performance of semiempirical PERTCI calculations of Koopmans ionizations is presented.

2 The terms "molecule" and "ion" are used throughout to specify a neutral or charged species, respectively.

Reprint requests to Prof. Dr. A. Schweig, Fachbereich Physikalische Chemie, Universität Marburg, Hans-Meerwein-Straße, D-3550 Marburg, FRG. phenyl $]^{+},[\text {diphenylacetylene }]^{+},[\text {benzocyclobutene }]^{+}$, and [o-xylylene] $]^{+}$.

To this end a detail of the LNDO/S method had to be altered. In the original version [2] (which was exclusively devoted to the prediction of electronic spectra of molecules) the computation of oscillator strengths was based on the closed shell component of the ground state CI vector alone (this simplified the calculations drastically and, at the same time, was a rather good approximation since the contribution of the closed shell component typically amounts to more than $95 \%$ for a molecule). Since the LNDO/S PERTCI approach uses molecular orbitals in the ion calculations, too the contribution of the main Koopmans configuration is generally much lower than $95 \%$ thus making it necessary to introduce the full ion ground state $\mathrm{CI}$ vector into the computation of the oscillator strengths. As a benefit the improved method of calculation yields better (i.e. lower) values for molecules, too as it is documented in Table 1, e.g., for ethylene $[9,11]$, transbutadiene $[9,12]$, all-trans-hexatriene $[10,13-16]$, and all-trans-octatetraene [13-16].

Since it has become standard in our semiempirical PERTCI calculations on molecules to use (whenever experimental data are unavailable) MNDO [17] optimized geometries we rely - also in the present work on cations (which are currently out of the realm of experimental structural methods) - on the MNDO optimized geometry of the ion ground states using the half-electron formalism [18-21]. 
Table 1. LNDO/S PERTCI transition energies and oscillator strengths for the lowest energy transition of ethylene, trans-butadiene, all-trans-hexatriene and all-trans-octatetraene.

\begin{tabular}{|c|c|c|c|c|c|c|}
\hline \multirow{2}{*}{$\begin{array}{l}\text { Molecule, } \\
\text { point group, ground state }\end{array}$} & \multirow{2}{*}{$\begin{array}{l}\text { Excited } \\
\text { state }\end{array}$} & \multicolumn{2}{|c|}{$\Delta E^{\mathrm{a}, \mathrm{b}}$} & \multicolumn{3}{|l|}{$f^{\mathrm{c}}$} \\
\hline & & calc. & obs. & calc. ${ }^{d}$ & calc. $^{e}$ & obs. \\
\hline $\begin{array}{l}\text { Ethylene, } \\
\mathrm{D}_{2 \mathrm{~h}},{ }^{1} \mathrm{~A}_{\mathrm{g}}{ }^{\mathrm{f}}\end{array}$ & ${ }^{1} \mathrm{~B}_{2 \mathrm{u}}(\pi)$ & 7.82 & $7.65^{i}$ & 0.46 & 0.33 & $0.34^{i, 1}$ \\
\hline $\begin{array}{l}\text { trans-Butadiene, } \\
\mathrm{C}_{2 \mathrm{~h}},{ }^{1} \mathrm{~A}_{\mathrm{g}}{ }^{\mathrm{f}}\end{array}$ & ${ }^{1} \mathrm{~B}_{\mathrm{u}}(\pi)$ & 6.18 & $5.93^{j}$ & 0.78 & 0.60 & $0.53^{\mathrm{j}, 1}$ \\
\hline $\begin{array}{l}\text { all-trans-Hexatriene, } \\
\mathrm{C}_{2 \mathrm{~h}},{ }^{1} \mathrm{~A}_{\mathrm{g}} \mathrm{g}\end{array}$ & ${ }^{1} \mathrm{~B}_{\mathrm{u}}(\pi)$ & 5.13 & $5.09^{k}$ & 1.25 & 0.99 & $(\sim 0.7)^{\mathrm{m}, \mathrm{n}, \mathrm{o}, \mathrm{p}}$ \\
\hline $\begin{array}{l}\text { all-trans-Octatetraene, } \\
\mathrm{C}_{2 \mathrm{~h}},{ }^{1} \mathrm{~A}_{\mathrm{g}} \mathrm{h}\end{array}$ & ${ }^{1} \mathrm{~B}_{\mathrm{u}}(\pi)$ & 4.74 & $4.61^{\mathrm{k}}$ & 1.72 & 1.40 & $(\sim 0.9)^{\mathrm{m}, \mathrm{n}, \mathrm{o}, \mathrm{p}}$ \\
\hline
\end{tabular}

a Transition energy. ${ }^{b}$ All values in eV. c Oscillator strength.

d Using only the ground state configuration of the ground state CI wavefunction.

e Using the full ground state CI wavefunction. $f$ Calculations based on the experimental geometry of [9].

$\mathrm{g}$ Calculations based on the experimental geometry of [10]. ${ }^{\mathrm{h}}$ Calculations based on the MNDO optimized geometry.

$i$ Value taken from [11]. $\mathrm{j}$ Value taken from [12]. $\mathrm{k}$ Value taken from [13]. ${ }^{1}$ Spectrum recorded in gas phase.

$\mathrm{m}$ Value taken from [14]. ${ }^{\mathrm{n}}$ No experimental details given in [14]; values probably uncertain.

- For 1,6-dimethylhexatriene and 1,8-dimethyloctatetraene 1.11 and 1.66 were observed, see [15].

p For 1,6-diphenylhexatriene and 1,8-diphenyloctatetraene 1.26 and 1.39 were observed, respectively, see [16].

Table 2. LNDO/S PERTCI transition energies, oscillator strengths and relative integrated absorption coefficients for the two lowest energy transitions of trans-butadiene, all-trans-hexatriene and all-trans-octatetraene radical cations. The calculations are based on both the molecular and ion ground state geometries.

\begin{tabular}{|c|c|c|c|c|c|c|c|c|c|}
\hline \multirow{2}{*}{$\begin{array}{l}\text { Cation, } \\
\text { point group, } \\
\text { ground state }\end{array}$} & \multirow{2}{*}{$\begin{array}{l}\text { Excited } \\
\text { state }\end{array}$} & \multicolumn{3}{|c|}{ Calculated $^{\text {a }}$} & \multicolumn{3}{|c|}{ Calculated ${ }^{\mathrm{b}}$} & \multicolumn{2}{|c|}{ Observed $\mathrm{c}, \mathrm{d}$} \\
\hline & & $\Delta E^{\mathrm{e}, \mathrm{f}}$ & $f^{\mathrm{g}}$ & $A_{\mathrm{r}}{ }^{\mathrm{h}}$ & $\Delta E^{\mathrm{e}, \mathrm{f}}$ & $f^{\mathrm{g}}$ & $A_{\mathrm{r}}{ }^{\mathrm{h}}$ & $\Delta E^{\mathrm{e}, \mathrm{f}}$ & $A_{\mathrm{r}}{ }^{\mathrm{h}}$ \\
\hline [trans-Butadiene] $]^{+}$, & $1^{2} \mathrm{~A}_{\mathrm{u}}(\pi)$ & 2.66 & 0.10 & 0.21 & 2.68 & 0.015 & 0.024 & 2.32 & 0.15 \\
\hline $\mathrm{C}_{2 \mathrm{~h}}, 1^{2} \mathrm{~B}_{\mathrm{g}}(\pi)^{\mathrm{i}}$ & $2^{2} A_{u}(\pi)$ & 4.73 & 0.47 & 1 & 4.22 & 0.62 & 1 & 4.20 & 1 \\
\hline$[\text { all-trans-Hexatriene }]^{+}$, & $1^{2} \mathrm{~B}_{\mathrm{g}}(\pi)$ & 2.20 & 0.16 & 0.19 & 2.18 & 0.018 & 0.018 & 1.92 & 0.05 \\
\hline$C_{2 h}, 1^{2} A_{u}(\pi)^{j}$ & $2^{2} B_{g}(\pi)$ & 3.80 & 0.82 & 1 & 3.42 & 0.99 & 1 & 3.27 & 1 \\
\hline 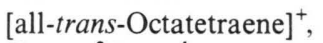 & $1^{2} \mathrm{~A}_{\mathrm{u}}(\pi)$ & 1.80 & 0.25 & 0.22 & 1.85 & 0.018 & 0.013 & 1.67 & 0.04 \\
\hline $\mathrm{C}_{2 \mathrm{~h}}, 1^{2} \mathrm{~B}_{\mathrm{g}}(\pi)^{\mathrm{k}}$ & $2{ }^{2} A_{u}(\pi)$ & 3.30 & 1.12 & 1 & 2.96 & 1.38 & 1 & 2.77 & 1 \\
\hline
\end{tabular}

a Calculations based on the molecular ground state geometry. b Calculations based on the ion ground state geometry.

c Experimental values taken from [22]. ${ }^{d}$ In an argon matrix. e Transition energy. ${ }^{\mathrm{f}}$ All values in eV.

$\mathrm{g}$ Oscillator strength. ${ }^{\mathrm{h}}$ Relative integrated absorption coefficient.

i Experimental molecular ground state geometry taken from [9]; ion ground state geometry MNDO optimized.

j Experimental molecular ground state geometry taken from [10]; ion ground state geometry MNDO optimized.

k Molecular and ion ground state geometries MNDO optimized.

\section{|trans-Butadiene $]^{+}$; [all-transHexatriene $]^{+}$; [all-trans-Octatetraene] ${ }^{+}$}

Table 2 lists calculated $\Delta E, f$ and $A_{\mathrm{r}}$ values $\left(A_{\mathrm{r}}\right.$ denotes the relative integrated absorption coefficient, the values being obtained from the $f$ values by arbitrarily setting $A_{\mathrm{r}}=1$ for the second intense transition) using the geometries of the molecular and ion ground states as well as observed $\Delta E$ and $A_{\mathrm{r}}$ data (to simplify, the Table contains the observed data of one research group only [22]; for further data the reader is referred to [23-33] quoted hereafter for the various systems) for [trans-butadiene] ${ }^{+}$ [23-25], [all-trans-hexatriene] ${ }^{+}[25-30]$ and [alltrans-octatetraene $]^{+}[31-33]$.

Using the ion instead of the molecular ground state geometry (which means switching from a pronounced bond alternation to a less pronounced one) has two main effects: (i) The value of the second transition energy is drastically improved (i.e. reduced by ca. $0.5 \mathrm{eV}, 0.4 \mathrm{eV}$, and $0.3 \mathrm{eV}$ for the three systems, respectively) and (ii) the values of 
the relative integrated absorption coefficient are markedly diminished (by an order of magnitude) for the first transition.

Both effects have recently [34] been obtained making an ad hoc assumption for the ion geometries; the agreement, however, between the results of [34] $\left(A_{\mathrm{r}}\right.$ values for the first transition: 0.014 and 0.011 for [all-trans-hexatriene] ${ }^{+}$and [all-trans-octatetraene $]^{+}$, respectively) and the present one is satisfactory. The corresponding $A_{\mathrm{r}}$ value for [transbutadiene] $]^{+}$is not given in [34]; this is very unfortunate because of the large discrepancy between the LNDO/S PERTCI prediction of 0.024 and the observed value of 0.15 [22] for this system. While we cannot see any reason from the theoretical point of view for expecting such a marked step in the series of $A_{\mathrm{r}}$ values $0.013,0.018$ and 0.024 in going from the hexatriene to the butadiene system we are well aware of the serious experimental problems of getting "pure" cation UV/VIS spectra. But whatever the reason for the aforementioned discrepancy is this point deserves some future attention.

When we compared $[5,6]$ the LNDO/S PERTCI ionization spectra including non-Koopmans ionizations with data obtained from the photoelectron spectra of butadiene, hexatriene and octatetraene and the UV/VIS spectra of the corresponding cations (see particularly the Tables of [6] as well as Table I to III of [22]) the inferior agreement between the calculated non-Koopmans state energies $\left[2^{2} \mathrm{~A}_{\mathrm{u}}(\pi)\right.$ for trans-butadiene and all-trans-octatetraene and $2^{2} \mathrm{~B}_{\mathrm{g}}(\pi)$ for all-trans-hexatriene] using the molecular geometry and the state energies derived from the observed UV/VIS spectra of the corresponding ions was obvious. It is gratifying to note (in the light of the present calculations) that this discrepancy was not due to a defect of the LNDO/S PERTCI approach but simply to the fact that a polyene molecule is a rather bad model for the corresponding ion $[34,35]$.

\section{[cis-Butadiene $]^{+}$; [all-cis-Hexatriene $]^{+}$}

Since even less is known about the structure of these cations some MNDO results will be discussed first. [cis-Butadiene] ${ }^{+}$comes out to be practically planar (point group $\mathrm{C}_{2 \mathrm{v}}$ ) and is by ca. $1.8 \mathrm{kcal} / \mathrm{mol}$ less than the [trans-butadiene] ${ }^{+}$counterpart which according to the MNDO optimization is planar (point group $\mathrm{C}_{2 \mathrm{~h}}$ ). According to the MNDO approach [all-cis-hexatriene] ${ }^{+}$is non-planar (a chiral system) being $28^{\circ}$ twisted around the central "double" bond and $20^{\circ}$ about the two "single" bonds (point group $\mathrm{C}_{2}$ ); it is by ca. $8.5 \mathrm{kcal} / \mathrm{mol}$ less stable than planar [all-trans-hexatriene] ${ }^{+}$and more stable by $5 \mathrm{kcal} / \mathrm{mol}$ than planar [all-cis-hexatriene] ${ }^{+}$ (point group $\mathrm{C}_{2 \mathrm{v}}$ ). Although we do not feel that the MNDO method is very reliable in locating conformers (this is from our experience over the years as well as from results given in the present paper, see results and discussion in following sections) we think that the main structural results ([cis-butadiene ${ }^{+}$to be planar and [all-cis-hexatriene] ${ }^{+}$to be chiral) are right.

Based on these structures the spectroscopic data of Table 3 were obtained. Regarding the transition energies or relative integrated absorption coefficients the cis- and the trans-butadiene-cations could be hardly distinguished one from the other. The only remarkable change in the data of the cisrelative to the trans-system is the drop in the oscillator strength ( 0.62 to 0.42$)$. To our knowledge the UV/VIS spectrum of [cis-butadiene] ${ }^{+}$is unknown. Its UV-VIS spectrum would be (according to the theoretical data) hard to distinguish from the one of the corresponding trans-species. A comparison of corresponding data of Tables 2 and 3 reveals drastical changes to occur in the electronic spectra of all-cis- relative to all-trans-hexatriene: For the first transition $A_{\mathrm{r}}$ drops to a very low value and both the $\Delta E$ and $f$ values of the second transition are strongly reduced (by $0.4 \mathrm{eV}$ and $70 \%$, respectively). These changes are in accord with the experimental findings $[29,30]$, in particular the intensity of the first band turned out to be such low that the authors of ref. [30] noted for this band "uncertain evidence for band" (cf. also Fig. 1 which exhibits the observed and calculated spectra of allcis- and all-trans-hexatriene).

\section{[trans-Stilbene $]^{+}$}

According to the MNDO optimization [transstilbene] ${ }^{+}$is planar (point group $\mathrm{C}_{2 \mathrm{~h}}$, ground state $1^{2} \mathrm{~A}_{\mathrm{u}}(\pi)$ ) in contrast to the molecule which is known to be non-planar with each phenyl group being rotated 32 degrees around the C-phenyl bonds [36, 37] (point group $\mathrm{C}_{2}$ ). By the way the MNDO 

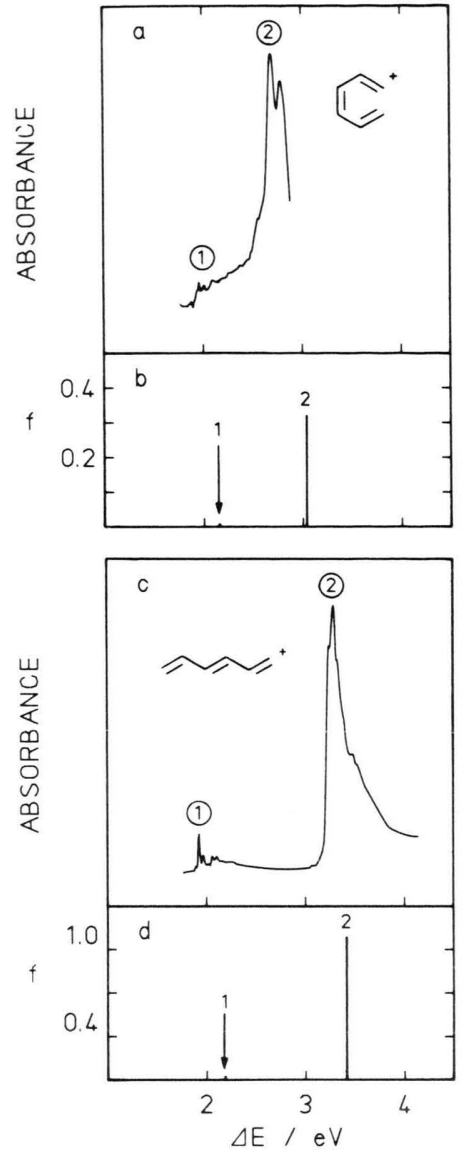

Fig. 1. (a) UV/VIS spectrum of [all-cis-hexatriene] ${ }^{+}$in an argon matrix [30]; (1) and (2) signify separate electronic bands. (b) LNDO/S PERTCI electronic spectrum of [allcis-hextatriene $]^{+}$; point group: $\mathrm{C}_{2}$; ground state: $1^{2} \mathrm{~B}(\pi)$; the excited electronic states are numbered in the order of increasing energy; the assignments are: (1) $1^{2} \mathrm{~A}(\pi)$, (2) $2^{2} \mathrm{~A}(\pi)$. (c) UV/VIS spectrum of [all-trans-hexatriene] ${ }^{+}$ in an argon matrix [30]; (1) and (2) signify separate electronic bands. (d) LNDO/S PERTCI electronic spectrum of [all-trans-hexatriene] ${ }^{+}$; point group: $\mathrm{C}_{2 \mathrm{~h}}$; ground state: $1^{2} \mathrm{~A}_{\mathrm{u}}(\pi)$; the excited electronic states are numbered in the order of increasing energy; the assignments are: (1) $1^{2} \mathrm{~B}_{\mathrm{g}}(\pi)$, (2) $2^{2} \mathrm{~B}_{\mathrm{g}}(\pi)$.

approach yields $\theta$ (angle of rotation) $=68$ degrees for the molecule thus drastically exaggerating nonplanarity (note $\theta=0$ in the coplanar case).

Figure 2 exhibits $\Delta E$ and $f$ as a function of $\theta$ for the three lowest relevant transitions (full lines; note that a transition of very weak oscillator strength, namely the transition to excited state $1\left[2^{2} \mathrm{~A}_{\mathrm{u}}(\pi)\right]$ with $\Delta E(f)$ varying from $1.87 \mathrm{eV}(0.0005)$ to $1.13 \mathrm{eV}(0.003)$ in the range of $\theta=10$ to 60 degrees
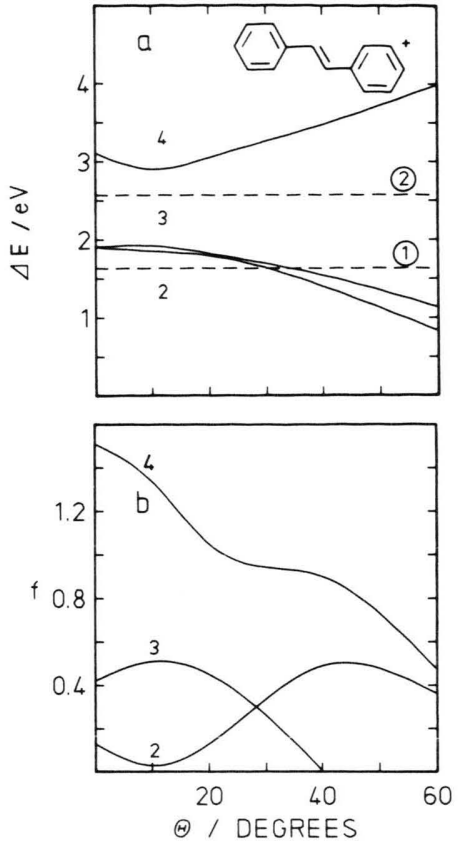

Fig. 2. (a) LNDO/S PERTCI transition energies $\Delta E$ as a function of the angle of rotation $\theta$ of the phenyl rings about the $\mathrm{C}$-phenyl bonds for the three relevant transitions 2,3 and 4 of [trans-stilbene] ${ }^{+}$; point group: $\mathrm{C}_{2 \mathrm{~h}}$ for the planar ion and $\mathrm{C}_{2}$ for the twisted one; ground state: $1^{2} A_{u}(\pi)$ in point group $C_{2 h}$ and $1^{2} A(\pi)$ in point group $C_{2}$; the excited electronic states are numbered in the order of increasing energy; the assignments are: (1) $2^{2} \mathrm{~A}_{\mathrm{u}}(\pi)$ : omitted, (2) $1{ }^{2} \mathrm{~B}_{\mathrm{g}}(\pi)$, (3) $2^{2} \mathrm{~B}_{\mathrm{g}}(\pi)$, (4) $3^{2} \mathrm{~B}_{\mathrm{g}}(\pi)$ in $\mathrm{C}_{2 \mathrm{~h}}$ and (1) $2^{2} \mathrm{~A}(\pi)$ : omitted, (2) $1^{2} \mathrm{~B}(\pi)$, (3) $2^{2} \mathrm{~B}(\pi),(4) 3^{2} \mathrm{~B}(\pi)$ in $\mathrm{C}_{2}$; dotted lines: observed absorption maxima for bands (1) and (2) of [39]. (b) LNDO/S PERTCI oscillator strengths $f$ as a function of $\theta$ for the three relevant transitions (see above).

has been omitted to simplify the Figure). As it can be seen the sum of the oscillator strengths of transitions to states 2 and 3 (which are very close in energy) is ca. 0.5 and practically constant in the range of $\theta=0$ to 40 degrees. Thus $\left(f_{2}+f_{3}\right) / f_{4}$ (according to Fig. 2) sensibly depends on $\theta$ and varies according to our calculations from 0.6 for $\theta=40$ degrees to 0.35 for $\theta=0$ degrees.

To our knowledge the UV/VIS absorption spectrum of [trans-stilbene $]^{+}$has not been recorded in an argon matrix but only in frozen $\mathrm{CCl}_{4}$ [38] and freon $[39,40]$ matrices. The absorption maxima were found, for bands (1) and (2), at $1.7 \mathrm{eV}$ and $2.5 \mathrm{eV}$ (these data are estimated from the published spectrum [38]), $1.63 \mathrm{eV}$ and $2.57 \mathrm{eV}$ [39] and $1.64 \mathrm{eV}$ and $2.59 \mathrm{eV}$ [40], respectively. The observed energies of 
[39] are represented as dotted lines in Figure 2. Hence there is no doubt that the excited ion states 2 and 3 , i.e. $1{ }^{2} \mathrm{~B}_{\mathrm{g}}(\pi)$ and $2^{2} \mathrm{~B}_{\mathrm{g}}(\pi)$, as well as excited state 4 , i.e. $3^{2} \mathrm{~B}_{\mathrm{g}}(\pi)$, are to be assigned to bands (1) and (2) of the UV/VIS spectrum, respectively (cf. also Figure 3 which shows the observed and calculated spectra). The assignment gets further support from a comparison of the calculated $\left(f_{2}+f_{3}\right) / f_{4}$ (see above) and the observed $f_{(1)} / f_{(2)}$ relative oscillator strength [39]. The measured value is 0.268 in the freon matrix and is thus closest to the value of ca. 0.35 for the planar geometry. This result votes - in harmony with the MNDO optimization - for [transstilbene $]^{+}$to be planar.

Our spectroscopic assignments as well as the calculated trend in the relative oscillator strength are in full accord with the results of a recently published calculation [41].

\section{[Biphenyl] ${ }^{+}$}

The MNDO calculations yield a dihedral angle of 32 degrees [point group $\mathrm{D}_{2}$, ground state $1^{2} \mathrm{~B}_{2}(\pi)$ ] for [biphenyl] ${ }^{+}$. The molecule has a dihedral angle $(\theta)$ of ca. 42 degrees in the gas phase [42] $(\theta=0$ for coplanar phenyl groups). The MNDO value for the molecule is 87 degrees again overrating non-planarity markedly. This fact as well as the finding that the dihedral angle is considerably reduced for the molecule in argon matrices [43] votes for [biphenyl] ${ }^{+}$ to be probably more on the planar side [point group $D_{2 h}$, ground state $1^{2} B_{2 g}(\pi)$ ] in an argon matrix than to be twisted by ca. 30 degrees (for a detailed discussion of the geometry of the cation see [44]).

Figure 4 shows the graphs of the functions $\Delta E(\theta)$ and $f(\theta)$ for the relevant transitions and Fig. 5 exhibits the observed UV/VIS [44, 45] and the calculated electronic excitation spectrum for $\theta=0$ degrees considering all transitions occurring between $\Delta E 1.0$ and $4.5 \mathrm{eV}$. Thus for planar $\left(\mathrm{D}_{2 \mathrm{~h}}\right)$ or moderately twisted $\left(\mathrm{D}_{2}\right)$ [biphenyl] ${ }^{+}$there is no doubt that the transitions to excited states 3 $\left[1^{2} \mathrm{~B}_{3 \mathrm{u}}(\pi)\right.$ or $\left.1{ }^{2} \mathrm{~B}_{3}(\pi)\right]$ and $4\left[2^{2} \mathrm{~B}_{3 \mathrm{u}}(\pi)\right.$ or $\left.2^{2} \mathrm{~B}_{3}(\pi)\right]$ have to be assigned to bands (1) and (2) in the UV/VIS spectrum [44, 45] which is in agreement with the assignments of [44, 46] and [45], respectively.

The nature of band (3) [44] of the UV/VIS spectrum deserves some special comments. This band

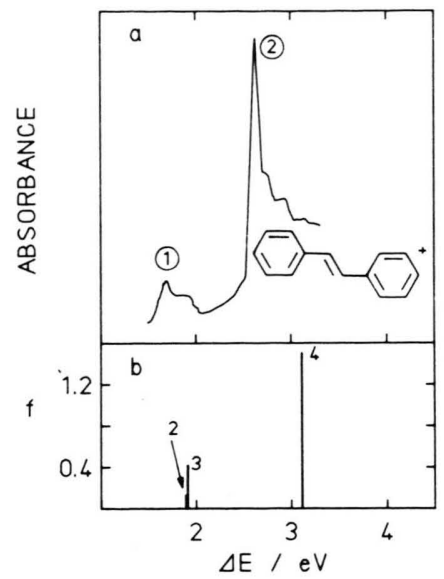

Fig. 3. (a) UV/VIS spectrum of [trans-stilbene] $]^{+}$in a freon matrix [40]; (1) and (2) signify separate electronic bands (according to literature assignments). (b) LNDO/S PERTCI electronic spectrum of planar [trans-stilbene] ${ }^{+}$; ground state in $\mathrm{C}_{2 h}: 1^{2} \mathrm{~A}_{u}(\pi)$; excited electronic states in the order of increasing energy in $\mathrm{C}_{2 \mathrm{~h}}$ : (1) $2^{2} \mathrm{~A}_{\mathrm{u}}(\pi)$ : omitted, (2) $1{ }^{2} \mathrm{~B}_{\mathrm{g}}(\pi)$, (3) $2^{2} \mathrm{~B}_{\mathrm{g}}(\pi)$, (4) $3^{2} \mathrm{~B}_{\mathrm{g}}(\pi)$.

was not assigned in [44, 45]. Present (as well as CNDO/S [47] PERTCI and MNDO PERTCI) calculations do not yield an appropriate transition (for the planar system). Thus we are left with several possibilities: (i) band (3) cannot be considered to be due to a separate electronic transition; (ii) the PERTCI method fails in predicting an appropriate transition; (iii) band (3) can be assigned to the transition to excited state $5\left[1^{2} \mathrm{~B}_{3 \mathrm{~g}}(\sigma)\right.$ or $\left.3^{2} \mathrm{~B}_{3}(\sigma)\right]$. For planar [biphenyl] ${ }^{+}$this transition is "forbidden" but its oscillator strength increases markedly with increasing $\theta$ as the explicit calculations show (Figure 4). Thus, even if $\theta$ (equilibrium) $=0$ (i.e. for the planar cation), averaging the oscillator strength over the torsional mode makes this transition rather strongly allowed. To say the same in other words: transition 5 [excited state $1^{2} \mathrm{~B}_{3 \mathrm{~g}}(\sigma)$ ] gets intensity by vibronic coupling to excited states 3 and $4\left[2^{2} B_{3 u}(\pi)\right.$ and $1{ }^{2} \mathrm{~B}_{3 \mathrm{u}}(\pi)$ ] through the torsional mode [note: ${ }^{2} \mathrm{~B}_{3 \mathrm{~g}}(\sigma) \times \mathrm{A}_{\mathrm{u}}$ (torsional mode) $\left.={ }^{2} \mathrm{~B}_{3 \mathrm{u}}(\pi)\right]$. The problem deserves further consideration, especially since band (3) appears to be present in the UV/VIS spectrum of [fluorene] ${ }^{+}[45]$, too.

Finally attention is drawn to transition 1 [to excited state $1^{2} \mathrm{~A}_{\mathrm{u}}(\pi)$ ] at $1.53 \mathrm{eV}, f=0.0062$ (note that transition 2 [to excited state $1^{2} \mathrm{~B}_{1 \mathrm{~g}}(\pi)$ ] is omitted since it is "forbidden" in the planar case and is 
Table 3. LNDO/S PERTCI transition energies, oscillator strengths and relative integrated absorption coefficients for the two lowest energy transitions of cis-butadiene and all-cis-hexatriene radial cations based on ion ground state geometries.

\begin{tabular}{|c|c|c|c|c|c|c|c|}
\hline \multirow{2}{*}{$\begin{array}{l}\text { Cation, } \\
\text { point group, ground state }\end{array}$} & \multirow{2}{*}{$\begin{array}{l}\text { Excited } \\
\text { state }\end{array}$} & \multicolumn{3}{|c|}{ Calculated } & \multicolumn{3}{|c|}{ Observed } \\
\hline & & $\Delta E^{\mathrm{a}, \mathrm{b}}$ & $f^{\mathrm{c}}$ & $A_{\mathrm{r}}{ }^{\mathrm{d}}$ & $\Delta E^{\mathrm{a}, \mathrm{b}}$ & $f^{\mathrm{c}}$ & $A_{\mathrm{r}}{ }^{\mathrm{d}}$ \\
\hline 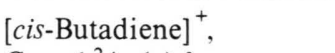 & $1^{2} \mathrm{~B}_{1}(\pi)$ & 2.66 & 0.011 & 0.027 & - & - & - \\
\hline $\mathrm{C}_{2 \mathrm{v}}, 1^{2} \mathrm{~A}_{2}(\pi)^{\mathrm{e}}$ & $2^{2} \mathrm{~B}_{1}(\pi)$ & 4.10 & 0.42 & 1 & - & - & - \\
\hline [all-cis-Hexatriene] $^{+}$, & $1^{2} \mathrm{~A}(\pi)$ & 2.15 & 0.0006 & 0.002 & $2.06^{\mathrm{f}, \mathrm{g}, \mathrm{i}}$ & - & - \\
\hline $\mathrm{C}_{2}, 1^{2} \mathrm{~B}(\pi)^{\mathrm{e}}$ & $2^{2} \mathrm{~A}(\pi)$ & 3.04 & 0.32 & 1 & $2.68^{f, g}$ & - & - \\
\hline a Transition energy. & d Relati & ted $a$ & tion $\mathrm{c}$ & ent. & $\mathrm{g} \mathrm{Ta}$ & $\mathrm{m}[3$ & \\
\hline b All values in eV. & e Ion grou & te geom & es MND & timized. & h Take & $\mathrm{m}[29$ & \\
\hline c Oscillator strength. & $\mathrm{f}$ In argon & $\begin{array}{l}\text { ices. } \\
\text { icentin }\end{array}$ & & & i Unce & evid & band. \\
\hline
\end{tabular}
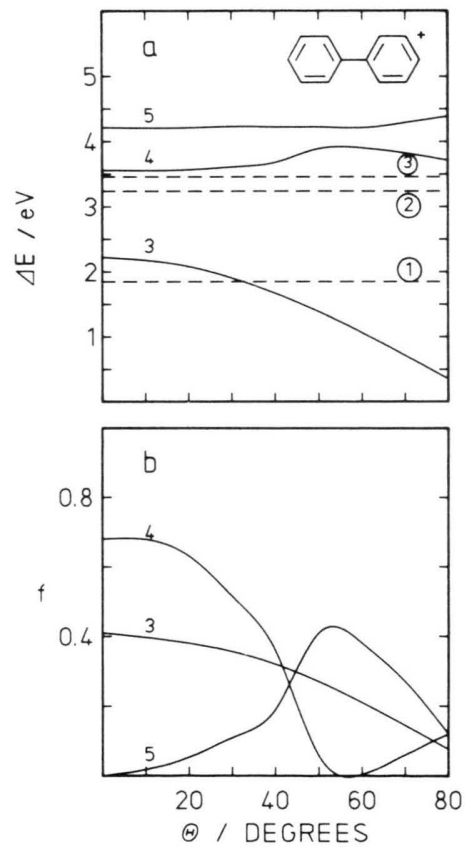

Fig. 4. LNDO/S PERTCI (a) transition energies $\Delta E$ and (b) oscillator strengths $f$ as a function of the dihedral angle $\theta$ for the three relevant transitions 3,4 , and 5 of [biphenyl] ${ }^{+}$. Ground state : $1^{2} \mathrm{~B}_{2 \mathrm{~g}}(\pi)$ or $1^{2} \mathrm{~B}_{2}(\pi)$ in $\mathrm{D}_{2 \mathrm{~h}}$ or $\mathrm{D}_{2}$; the excited states are numbered in order of increasing energy; with the assignments: (1) $1^{2} \mathrm{~A}_{\mathrm{u}}(\pi)$ : omitted, (2) $1{ }^{2} \mathrm{~B}_{1 \mathrm{~g}}(\pi)$ : omitted, (3) $1{ }^{2} \mathrm{~B}_{3 \mathrm{u}}(\pi)$; (4) $2^{2} \mathrm{~B}_{3 \mathrm{u}}(\pi)$, (5) $1{ }^{2} \mathrm{~B}_{3 \mathrm{~g}}(\sigma)$, in $\mathrm{D}_{2 \mathrm{~h}}$ or (1) $1^{2} \mathrm{~A}(\pi)$ : omitted, (2) $1^{2} \mathrm{~B}_{1}(\pi)$ : omitted, (3) $1{ }^{2} \mathrm{~B}_{3}(\pi)$, (4) $2^{2} \mathrm{~B}_{3}(\pi)$, (5) $3^{2} \mathrm{~B}_{3}(\sigma)$, in $\mathrm{D}_{2}$; dotted lines in part (a): observed absorption maxima for bands (1), (2), and (3) from [44]. of low intensity otherwise). An experimental search might be rewarding.

The absorption maxima were observed at $1.8 \mathrm{eV}$, $3.0 \mathrm{eV}, 3.5 \mathrm{eV}$ (estimated from the published spectrum) in frozen $\mathrm{CCl}_{4}$ [38] and $1.85 \mathrm{eV}, 3.24 \mathrm{eV}$, $3.46 \mathrm{eV}$ in an argon matrix [44] (note that the dotted lines given in Fig. 4 correspond to the latter data). The calculated electronic excitation energies for the first two transitions are: $2.22 \mathrm{eV}, 3.56 \mathrm{eV}$ for the planar cation meaning that the LNDO/S PERTCI spectrum is slightly shifted to higher energies.

\section{[Diphenylacetylene $]^{+}$}

The MNDO calculations predict [diphenylacetylene] ${ }^{+}$to be planar [point group $\mathrm{D}_{2 \mathrm{~h}}$; ground state $\left.1^{2} \mathrm{~B}_{3 \mathrm{u}}(\pi)\right]$. Nonetheless to estimate possible twisting effects we calculated the functions $\Delta E(\theta)$ and $f(\theta)$ ( $\theta$ is the dihedral angle between the phenyl planes; $\theta=0$ for the coplanar case) for the relevant transitions. The corresponding graphs are shown in Figure 6. The observed UV/VIS spectrum [48] and the calculated electronic spectrum for $\theta=0$ is shown in Figure 7.

The most interesting point with the UV/VIS spectrum of [diphenylacetylene] ${ }^{+}$is the assignment of bands. The assignments of [48] are: transitions to ${ }^{2} \mathrm{~B}_{1 \mathrm{~g}}(\pi),{ }^{2} \mathrm{~B}_{2 \mathrm{~g}}(\pi),{ }^{2} \mathrm{~B}_{2 \mathrm{~g}}(\pi)$ for bands (1), (2), (3), respectively with no assignment given to band (4). Our 


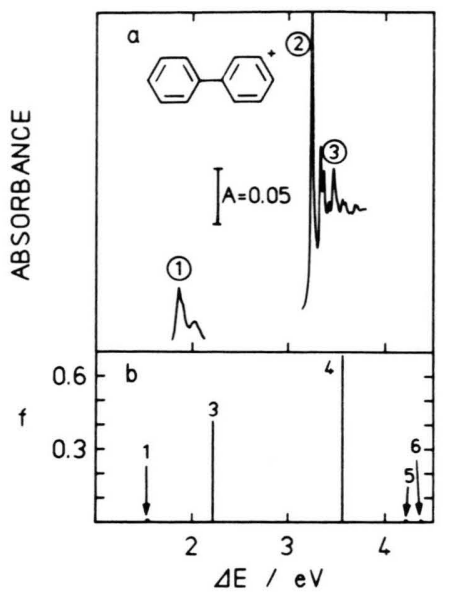

Fig. 5. (a) UV/VIS spectrum of [biphenyl] ${ }^{+}$in an argon matrix [44]; (1), (2), and (3) signify separate electronic bands. (b) LNDO/S PERTCI electronic spectrum of planar [biphenyl] + ; ground state in $\mathrm{D}_{2 \mathrm{~h}}: 1^{2} \mathrm{~B}_{2 \mathrm{~g}}(\pi)$; excited states numbered in the order of increasing energy with assignments in $\mathrm{D}_{2 \mathrm{~h}}$ as follows: (1) $1^{2} \mathrm{~A}_{\mathrm{u}}(\pi)$, (2) $1^{2} \mathrm{~B}_{1 \mathrm{~g}}(\pi)$, (3) $1{ }^{2} \mathrm{~B}_{3 \mathrm{u}}(\pi)$, (4) $2^{2} \mathrm{~B}_{3 \mathrm{u}}(\pi)$, (5) $1{ }^{2} \mathrm{~B}_{3 \mathrm{~g}}(\sigma)$.

calculation confirms only one of these assignments, namely the one of band (3) [transition 5 to excited state $2^{2} \mathrm{~B}_{2 \mathrm{~g}}(\pi)$ ]. Band (1) has to be assigned to transition 1 [to the excited state $1^{2} \mathrm{~B}_{2 \mathrm{~g}}(\pi)$ ]; transition 2 [to the excited state $1^{2} \mathrm{~B}_{1 \mathrm{~g}}(\pi)$ ] cannot account for the observed oscillator strength (oscillator strength of this transition is very weak over the whole range of angles considered). This raises the question about the assignment of band (2) (if it does be a separate electronic band). The calculations suggest that this band could be due to transition 4 [to state $1^{2} \mathrm{~B}_{2 \mathrm{u}}(\sigma)$ ] (note that, strictly, transition 4 should not appear in the excitation spectrum of Fig. 7 since it is "forbidden" for the planar cation; however it is shown since it may play a role in the assignments of bands; in this context it should further be noted that another excited state $3\left[{ }^{2} \mathrm{~A}_{\mathrm{u}}(\pi)\right]$ located in between states 1 and 4 has been omitted since it is forbidden in $D_{2 h}$ and has very weak oscillator strength in $\mathrm{D}_{2}$ for all angles considered). The reason for our proposal is the explicit calculation of the oscillator strength of transition 4 which assumes strong values for rather small angles. Thus vibrational averaging over the torsional mode makes the transition allowed or, to express it in the language of the vibronic coupling model, transition 4 borrows intensity from transitions 1 and 5 through vibronic coupling of $1^{2} \mathrm{~B}_{2 \mathrm{u}}(\sigma)$
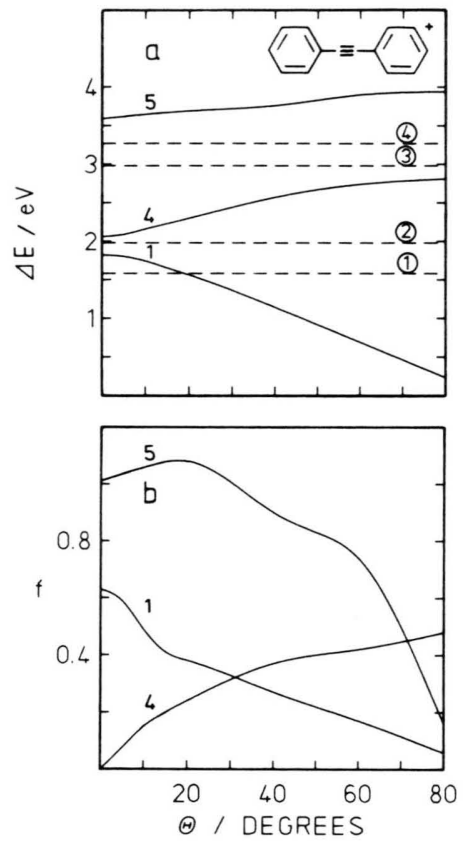

Fig. 6. LNDO/S PERTCI (a) transition energies $\Delta E$ and (b) oscillator strengths $f$ against the angle of rotation $\theta$ of the phenyl groups around the C-phenyl bonds $(\theta=0$ for the planar system) for the three relevant transitions 1,4 and 5 of [diphenylacetylene] ${ }^{+}$. Ground state in $\mathrm{D}_{2 \mathrm{~h}}\left[\mathrm{D}_{2}\right]$ : $1{ }^{2} \mathrm{~B}_{3 \mathrm{u}}(\pi)\left[1^{2} \mathrm{~B}_{3}(\pi)\right]$; excited states in the order of increasing energy in $D_{2 h}\left[D_{2}\right]$ : (1) $1^{2} B_{2 g}(\pi)\left[1^{2} B_{2}(\pi)\right]$, (2) $1^{2} B_{1 g}(\pi)$ [1 $\left.{ }^{2} \mathrm{~B}_{1}(\pi)\right]$ : omitted, (3) $1^{2} \mathrm{~A}_{\mathrm{u}}(\pi) \quad\left[1^{2} \mathrm{~A}(\pi)\right]$ : omitted, (4) $1{ }^{2} \mathrm{~B}_{2 \mathrm{u}}(\sigma)\left[2^{2} \mathrm{~B}_{2}(\sigma)\right]$, (5) $2^{2} \mathrm{~B}_{2 \mathrm{~g}}(\pi)\left[3^{2} \mathrm{~B}_{2}(\pi)\right]$; dotted lines in part (a): observed absorption maxima for bands (1), (2), (3), and (4) of [48].

to $1^{2} \mathrm{~B}_{2 \mathrm{~g}}(\pi)$ and $2^{2} \mathrm{~B}_{2 \mathrm{~g}}(\pi)$ by the torsional mode (of symmetry $A_{u}$ ).

The calculations (as well as CNDO/S PERTCI and MNDO PERTCI calculations) give no convincing hint about a possible assignment of peak (4) which was considered in [48] to be the onset of a separate electronic band. This point deserves further consideration.

The absorption maxima were observed at $1.53 \mathrm{eV}$, $1.9 \mathrm{eV}, 2.94 \mathrm{eV}, 3.2 \mathrm{eV}$ in a frozen freon matrix [39] (note that the maxima at $1.9 \mathrm{eV}$ and $3.2 \mathrm{eV}$ are not mentioned as separate electronic bands in [39]; we estimated them from the given spectra and quote them in analogy to the following data of [48]) and $1.58 \mathrm{eV}, 1.98 \mathrm{eV}, 2.98 \mathrm{eV}$, and $3.27 \mathrm{eV}$ [48] (note that the dotted lines of Fig. 6 refer to the latter data). The first three observed energies can be compared with theoretical excitation energies 


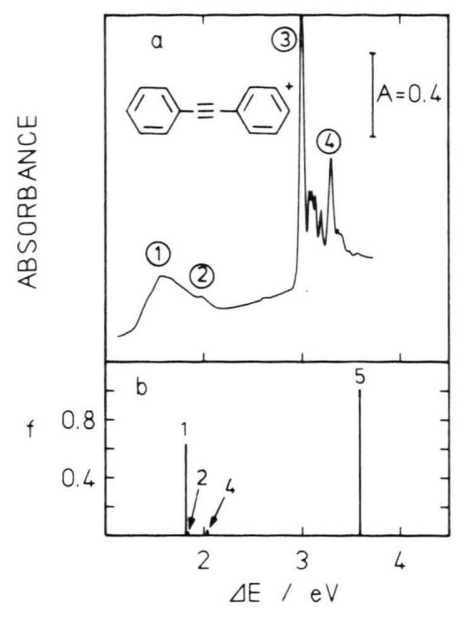

Fig. 7. (a) UV/VIS spectrum of [diphenylacetylene] ${ }^{+}$in an argon matrix [48]; (1), (2), (3) and (4) signify separate electronic bands. (b) LNDO/S PERTCI electronic excitation spectrum for planar [diphenylacetylene] ${ }^{+}$; ground state in $D_{2 h}: 1{ }^{2} B_{3 u}(\pi)$; excited electronic states in the order of increasing energy in $\mathrm{D}_{2 \mathrm{~h}}$ : (1) $1^{2} \mathrm{~B}_{2 \mathrm{~g}}(\pi)$, (2) $1^{2} \mathrm{~B}_{1 \mathrm{~g}}(\pi)$, (3) $1{ }^{2} \mathrm{~A}_{\mathrm{u}}(\pi)$ : omitted, (4) $1{ }^{2} \mathrm{~B}_{2 \mathrm{u}}(\sigma),(5) 2^{2} \mathrm{~B}_{2 \mathrm{~g}}(\pi)$.

$1.82 \mathrm{eV}, 2.06 \mathrm{eV}$, and $3.59 \mathrm{eV}$ for planar $\left(\mathrm{D}_{2 \mathrm{~h}}\right)$ [diphenylacetylene] ${ }^{+}$. Our assignments (tentative for band (2) are: $1{ }^{2} \mathrm{~B}_{2 g}(\pi)$ to band (1), $1{ }^{2} \mathrm{~B}_{2 \mathrm{u}}(\sigma)$ to band (2) and $2^{2} \mathrm{~B}_{2 \mathrm{~g}}(\pi)$ to band (3). The nature of band (4) stays unexplained.

\section{$[\text { Benzocyclobutene }]^{+} ;[\text {o-Xylylene }]^{+}$}

In [5] we concluded: "The photoelectron spectrum of o-xylylene and the UV/VIS spectrum of the corresponding cation are very much desired in order to examine the predictions made below." At the time MNDO PERTCI, CNDO/S PERTCI and LNDO/S PERTCI prediction was the sequence of ion states $1^{2} \mathrm{~A}_{2}(\pi)$ (ion ground state), $1^{2} \mathrm{~B}_{1}(\pi)$, $2^{2} \mathrm{~A}_{2}(\pi)$, and $2^{2} \mathrm{~B}_{1}(\pi)$ meaning that already the first excited ion state was a non-Koopmans state. The photoelectron spectrum was obtained [7] and strong evidence for the low-energy shake-up structure was presented from an analysis of the PE spectrum. A main problem in recording the PE spectrum of o-xylylene was the low activation energy for ring closure in this molecule to benzocyclobutene.

Meanwhile we succeeded - in a first attempt in recording the UV/VIS spectrum of X-ray irradiated benzocyclobutene (Figure 8 ). We tentatively

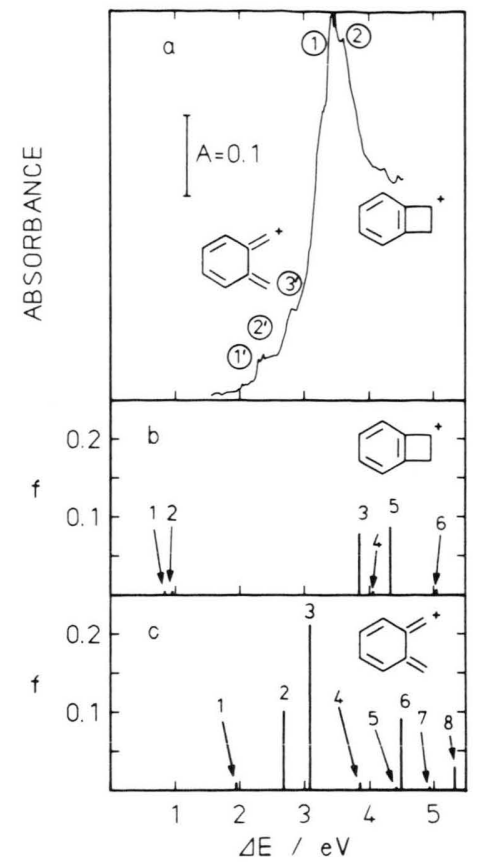

Fig. 8. (a) UV/VIS spectrum of X-ray irradiated benzocyclobutene in an argon matrix; (1) and (2) are tentatively attributed to absorption bands of [benzocyclobutene] $]^{+}$and (1)', (2)', and (3)' to absorption bands of [o-xylylene] ${ }^{+}$. (b) LNDO/S PERTCI electronic excitation spectrum of [benzocyclobutene] ${ }^{+}$; ground state in $\mathrm{C}_{2 \mathrm{v}}: 1^{2} \mathrm{~B}_{1}(\pi)$; excited states in the order of increasing energy: (1) $1^{2} \mathrm{~A}_{2}(\pi)$, (2) $1^{2} \mathrm{~A}_{1}(\sigma)$, (3) $2^{2} \mathrm{~B}_{1}(\pi)$, (4) $2^{2} \mathrm{~A}_{1}(\sigma)$, (5) $2^{2} \mathrm{~A}_{2}(\pi)$, $3^{2} \mathrm{~B}_{1}(\pi)$. (c) LNDO/S PERTCI electronic excitation spectrum of [o-xylylene] $]^{+}$; ground state in $\mathrm{C}_{2 \mathrm{v}}: 1^{2} \mathrm{~A}_{2}(\pi)$; excited states in the order of increasing energy: (1) $1^{2} \mathrm{~B}_{1}(\pi)$, (2) $2^{2} \mathrm{~A}_{2}(\pi)$, (3) $2^{2} \mathrm{~B}_{1}(\pi)$, (4) $3^{2} \mathrm{~B}_{1}(\pi)$, (5) $1^{2} \mathrm{~B}_{2}(\sigma),(6) 3^{2} \mathrm{~A}_{2}(\pi),(7) 2^{2} \mathrm{~B}_{2}(\sigma),(8) 4^{2} \mathrm{~B}_{1}(\pi)$.

attribute the spectrum to [benzocyclobutene] ${ }^{+}$and a small amount of [o-xylylene $]^{+}$present, on the following arguments.

The strong intensity structure in the UV/VIS spectrum is compatible with transitions 3 and 5 [from the ground state $1^{2} \mathrm{~B}_{1}(\pi)$ to the excited states $2^{2} \mathrm{~B}_{1}(\pi)$ and $2^{2} \mathrm{~A}_{2}(\pi)$, respectively] in the calculated (note all calculations for MNDO optimized geometries) electronic spectrum of [benzocyclobutene] ${ }^{+}$ (cf. Figure 8). The $2^{2} \mathrm{~B}_{1}(\pi)$ and $2^{2} \mathrm{~A}_{2}(\pi)$ bands (according to assignments made in [49] and our own ones) occur in the photoelectron spectrum of benzocyclobutene at ca. $3.1 \mathrm{eV}$ and $3.4 \mathrm{eV}$, respectively and hence could well correspond to "bands (1) and (2)" hidden under the high intensity structure of the UV/VIS spectrum (shoulders at ca. $3.3 \mathrm{eV}$ and 
$3.6 \mathrm{eV}$ ). Transition 1 [to excited state $1^{2} \mathrm{~A}_{2}(\pi)$ ] is calculated to occur at $0.83 \mathrm{eV}$ and would be expected from photoelectron spectroscopic data at $0.52 \mathrm{eV}$. Since our UV/VIS spectrometer poses a limit at $1.38 \mathrm{eV}(900 \mathrm{~nm})$ we could not examine the relevant region for absorption of light. It is interesting to note that transition 2 [to excited state $1^{2} \mathrm{~A}_{1}(\sigma)$, calculated to occur at $0.94 \mathrm{eV}$ ] is strongly shifted to lower excitation energy as a direct consequence of induced geometry changes in going from the molecule to the ion [note that - according to the photoelectron spectroscopic assignments - this state occurs at $2.07 \mathrm{eV}$ (obs.) and $2.52 \mathrm{eV}$ (calc. using LNDO/S PERTCI)].

The low intensity features (1)', (2)', and (3)' (which are reproducible under all circumstances) in UV/ VIS spectrum of Fig. 8 are observed at ca. $2.0 \mathrm{eV}$, $2.37 \mathrm{eV}$, and $2.8 \mathrm{eV}$. The first three excited ion states $1{ }^{2} \mathrm{~B}_{1}(\pi), 2^{2} \mathrm{~A}_{2}(\pi)$, and $2^{2} \mathrm{~B}_{1}(\pi)$ were observed (according to the photoelectron spectroscopic analysis of [7], see above) at ca. $1.9 \mathrm{eV}, 2.35 \mathrm{eV}$, and $2.79 \mathrm{eV}$ above the ground state. This good agreement as well as the theoretical finding that the three states are subject to only minor energy changes when going from the molecular ground state geometry (responsible for the ionization spectrum) to the ion ground state geometry (responsible for the excitation spectrum) suggests the possibility that features (1)', (2)', and (3) might be due to the electronic transitions 1,2 and 3 [from the ground state $1^{2} \mathrm{~A}_{2}(\pi)$ to the excited states $1^{2} \mathrm{~B}_{1}(\pi), 2^{2} \mathrm{~A}_{2}(\pi)$, and $2^{2} \mathrm{~B}_{1}(\pi)$, respectively] of [o-xylylene] ${ }^{+}$. Further work on [benzocyclobutene ${ }^{+}$and $[0-x y l y l e n e]^{+}$ including their photochemical behaviour is in progress.

[1] J. Kreile, N. Münzel, A. Schweig, and H. Specht, Chem. Phys. Lett. 124, 140 (1986).

[2] G. Lauer, K.-W. Schulte, and A. Schweig, J. Amer. Chem. Soc. 100, 4925 (1978).

[3] R. Schulz, A. Schweig, and W. Zittlau, J. Mol. Struct. Theochem. 121, 115 (1985).

[4] H.-L. Hase, G. Lauer, K.-W. Schulte, and A. Schweig, Theor. Chim. Acta 48, 47 (1978).

[5] R. Schulz, A. Schweig, and W. Zittlau, J. Amer. Chem. Soc. 105, 2980 (1983).

[6] R. Schulz, A. Schweig, and W. Zittlau, Chem. Phys. Lett. 106, 467 (1984).

[7] J. Kreile, N. Münzel, R. Schulz, and A. Schweig, Chem. Phys. Lett. 108, 609 (1984).

[8] A. Schweig and W. Zittlau, Chem. Phys. 103, 375 (1986).
To summarize, the present calculations have shown that the LNDO/S PERTCI method in conjunction with the MNDO optimization procedure is a suitable method for the calculation of electronic spectra of radical cations. Not only observed energies but also oscillator strengths are satisfactorily reproduced (in the frame of accuracies which can be expected for semiempirical approaches). Effects of geometry changes when going from a molecule (or its ionization spectrum) to its ion (or its electronic excitation spectrum) appear to be reasonably accounted for by the combined MNDO (for determining the geometry) and LNDO/S PERTCI (for evaluating the influence of the geometry on the electronic spectra) approaches. Thus the LNDO/S PERTCI method might be of considerable help in interpreting observed UV/VIS spectra of cations, elucidating interrelations between PE spectra of molecules and UV/VIS spectra of corresponding cations and, last not least in this way, in helping to identify radical cations or cationic products of cations. The various examples presented in the present paper might bear witness to the quality of these statements.

\section{Acknowledgements}

This work was supported by the Deutsche Forschungsgemeinschaft and the Fonds der Chemischen Industrie. The calculations were carried out on the Sperry 1100/62, IBM 4361 LO 4 and VAX 11/750 computers of the Rechenzentrum der Universität Marburg.

[9] L. E. Sutton, Tables of Interatomic Distances, The Chemical Society, London 1958, Suppl. 1965.

[10] M. Traetteberg, Acta Chem. Scand. 24, 2295 (1970).

[11] A. J. Merer and R. S. Mulliken, Chem. Rev. 69, 639 (1969).

[12] R. S. Mulliken, Rev. Mod. Phys. 14, 265 (1942).

[13] N. L. Allinger, J. C. Tai, and T. W. Stuart, Theor. Chim. Acta 8, 101 (1967).

[14] H. B. Klevens and J. R. Platt, J. Chem. Phys. 17, 470 (1949).

[15] P. Nayler and M. C. Whiting, J. Chem. Soc. 1955, 3037.

[16] A. Macoll, Quart. Rev. 1, 16 (1947).

[17] M. J. S. Dewar and W. Thiel, J. Amer. Chem. Soc. 99, 4899 (1977). 
[18] H. C. Longuet-Higgins and J. A. Pople, Proc. Phys. Soc. London A 68, 591 (1955).

[19] M. J. S. Dewar, J. A. Hashmall, and C. G. Venier, J. Amer. Chem. Soc. 90, 1953 (1968).

[20] F. O. Ellison and F. M. Matheu, Chem. Phys. Lett. 10, $322(1971)$.

[21] M. J. S. Dewar and N. Trinajstić, Chem. Commun. $1970,646$.

[22] T. Bally, S. Nitsche, K. Roth, and E. Haselbach, J. Amer. Chem. Soc. 106, 3927 (1984).

[23] T. Shida, Kagaku no Ryoiki 30, 31 (1976).

[24] R. C. Dunbar, Chem. Phys. Lett. 32, 508 (1975).

[25] V. E. Bondybey, J. H. English, and T. A. Miller, J. Mol. Spectrosc. 80, 200 (1980).

[26] T. Shida, T. Kato, and Y. Nosaka, J. Phys. Chem. 81, 1095 (1977)

[27] R. C. Dunbar and H. H.-I Teng, J. Amer. Chem. Soc. 100, 2279 (1978).

[28] M. Allan, J. Dannacher, and J. P. Maier, J. Chem. Phys. 73, 3114 (1980).

[29] B. J. Kelsall and L. Andrews, J. Phys. Chem. 88, 2723 (1984).

[30] T. Bally, S. Nitsche, K. Roth, and E. Haselbach, J. Phys. Chem. 89, 2528 (1985)

[31] T. B. Jones and J. P. Maier, Int. J. Mass Spectrom. Ion Phys. 31, 287 (1979).

[32] I. R. Dunkin, L. Andrews, J. T. Lurito, and B. J. Kelsall, J. Phys. Chem. 89, 1701 (1985).

[33] T. Bally, S. Nitsche, and K. Roth, J. Chem. Phys. 84, 2577 (1986).

[34] R. W. Bigelow, Int. J. Quant. Chem. 29, 35 (1986).

[35] T. Yamabe, K. Akagi, Y. Tanabe, K. Fukui, and H. Shirakawa, J. Phys. Chem. 86, 2359 (1982).
[36] M. Traetteberg, E. B. Frantsen, F. J. Mijlhoff, and A. Hoekstra, J. Mol. Struct. 26, 57 (1975).

[37] T. Kobayashi, H. Suzuki, and K. Ogawa, Bull. Chem. Soc. Japan 55, 1734 (1982).

[38] W. H. Hamill, Radical Ions (E. T. Kaiser and L. Kevan, eds.), Wiley-Interscience, New York 1968, p. 321 .

[39] H. Suzuki, K. Koyano, T. Shida, and A. Kira, Bull. Chem. Soc. Japan 55, 3690 (1982).

[40] E. Haselbach, U. Klemm, R. Gschwind, T. Bally, L. Chassot, and S. Nitsche, Helv. Chim. Acta 65, 2464 (1982).

[41] R. W. Bigelow, Chem. Phys. Lett. 117, 22 (1985).

[42] A. Almenningen, A. O. Hartmann, and H. M. Seip, Acta Chem. Scand. 22, 1013 (1968) and references therein.

[43] L. Le Gall and S. Suzuki, Chem. Phys. Lett. 46, 467 (1977).

[44] A. C. Puiu, L. Andrews, W. A. Chupka, and S. D. Colson, J. Chem. Phys. 76, 3854 (1982)

[45] L. Andrews, R. T. Arlinghaus, and C. K. Payne, J. Chem. Soc. Faraday Trans. 2, 885 (1983).

[46] J. P. Maier and D. W. Turner, Faraday Discuss. Chem. Soc. 54, 149 (1972).

[47] K.-W. Schulte and A. Schweig, Theor. Chim. Acta 33, 19 (1974) and references therein.

[48] B. J. Kelsall, R. T. Arlinghaus, and L. Andrews, High Temperature Science 17, 155 (1984).

[49] F. Brogli, W. Giovannini, E. Heilbronner, and R. Schurter, Chem. Ber. 106, 961 (1973). 